\title{
A CONCERN ABOUT YOUNGER DRIVERS IN PERTH
}

\author{
Z. EBRAHIM \& H. NIKRAZ \\ Department of Civil Engineering, Curtin University, Australia.
}

\begin{abstract}
This paper highlights the concerns about younger drivers in Perth. Evidence suggests that this group of drivers were speeding at different levels particularly the highly excessive. Despite $60 \mathrm{~km} / \mathrm{h}$ being considered a higher speed limit than the other two limits under this study, it was found that younger drivers are speeding and taking higher risks on roads that belong to the 40 and $50 \mathrm{~km} / \mathrm{h}$ speed limits. The 'On the spot' detection found roads, which belong to $50 \mathrm{~km} / \mathrm{h}$, were also of concern. Male drivers were dominating the speeding on roads for the three speed limits roads studied. Pedestrian crash data also supported this evidence in concluding that the leading number of drivers who hit pedestrians belongs to this younger age group. Speeding and pedestrian crashes on $40 \mathrm{~km} / \mathrm{h}$ on non-school zone roads are also examined and discussed. It is recommended that along with enforcement, two levels policy need to be targeted in parallel. First, a safety audit to the 50 and $60 \mathrm{~km} / \mathrm{h}$ limits as a comprehensive municipal programme that may lower the limits to a safer speed on these roads needs to be adopted. Second, authorities may focus on younger drivers' licence regulations in terms of speeding violations and accidents history and real scenario training that relates to that age group. Such policy direction may bring high returns in sustaining safer roads.

Keywords: Chi-square, correspondence analysis, on the spot, pedestrian crashes young drivers, roadside, school zone.
\end{abstract}

\section{INTRODUCTION}

It has been mentioned numerously in literature that young drivers are of concern in terms of safety to themselves and to other road users particularly to the vulnerable pedestrians. An Australian longitudinal study found that young drivers are consistently over-represented among those injured or killed in road crashes [1]. Latest report revealed that fatality rates for young drivers aged up to 24 remain almost double their proportion of the population in Western Australia (WA) [2]. As male drivers in WA remain twice more likely to be killed while driving than female drivers [3]. The Monash University Accident Research Centre (MUARC) has focused on in the nineties to improving young drivers' safety within Victoria and the problems associates with their behaviour and particularly speeding [4]. Speeding is frequently linked as a cause of road crashes. It is well documented globally that travelling with lower speed can prevent crashes, reduce severities and most importantly save pedestrian lives [5]. According to the office of road safety in WA, around 34\% of fatal crashes had speeding as a contributing crash factor. Therefore lowering speed limits has been the initiatives of authorities all over Australia. For instance, a review of international speed limits (compared with other Organization for Economic Co-operation and Development (OECD) countries) found that Australia's limits tended to be higher than those found elsewhere, including in Europe and North America [6]. They recommended that to reduce road injuries further, more must be done to reduce driving speeds in Australia including lowering speed limits, which may be a critical component in achieving this outcome. The Austroads report revealed that European Union (EU) countries have utilised harm minimisation principles as the basis for setting speed limits. The necessity of adopting a speed limit is well documented in reference [7].

One of the vital intervention phases in road safety is to control speeding through enforcement, which can affect behaviours and make young drivers and other age group reduce their speed or stay within the legal posted speed limit. According to the OECD, enforcement is considered as a difficult task and believe that speeding remains the most widely spread offence [8]. It has been demonstrated 
by Elvik [9] that the more the enforcement, the greater the reduction in the number of crashes. The next section will discuss enforcement measures to three different speed limits.

The study will focus on younger drivers between the ages of 17 and 24 years as compared with young (25-29 years), middle age group (30-44 years), older middle (45-54) and old group is (55+ years). The younger age group was the focus as this group was over-represented in serious injury crashes in WA [10]. In addition to that the same age group accounted for a third of all serious and fatal crashes - despite making up only about $14 \%$ of the driving population [11]. According to a recent research, the WA Road Safety Council, showed that the same age group drivers are twice as likely as older drivers to die in an accident [12].

\section{SPEED LIMITS VIOLATION}

Three subsections are discussed below, the three speed limits, gender and age groups.

\subsection{Three speed limits}

The study covers 165 suburbs of the urban area of Perth. Total Traffic Infringement Notices (TINs) was 685,391 for the period of July 2007-June 2011. It examined the camera detection of three speed limits $(40,50$ and $60 \mathrm{~km} / \mathrm{h})$. Two detection types were used similar to that adopted in other major cities in Australia. The first type is the road side cameras placed inside a vehicle or on the ground both will be detecting speeders from the side of the road; they are referred to as 'road side' detection. The second type is the hand held cameras by police officers, which involves all pullovers, including the use of marked/unmarked cars, which will be referred to as 'on the spot' detection. The ratio of younger age group to the rest of all age group detection was computed and is shown in Fig. 1. Three observations may be noted. First, the higher the speed limits, the higher the ratio of young drivers speeding. This means that younger drivers are taking more risk in roads with higher posted speed limits such as 50 and $60 \mathrm{~km} / \mathrm{h}$. Second, regardless of detection type lower speeding rates are observed as speed limits are lowered. This means that regardless of detection types, younger drivers are taking more risk on higher speed limit roads. Third, all detection by 'on the spot' type has shown to record higher rate for younger drivers compared with 'roadside' detection.

It may suggest that by this method younger drivers are frequently detected speeding with higher speeding levels compared with the 'roadside' detection method. It can also be noticed that at $50 \mathrm{~km} / \mathrm{h}$ limits, some extreme speeding levels are also detected, which may indicate why authorities are

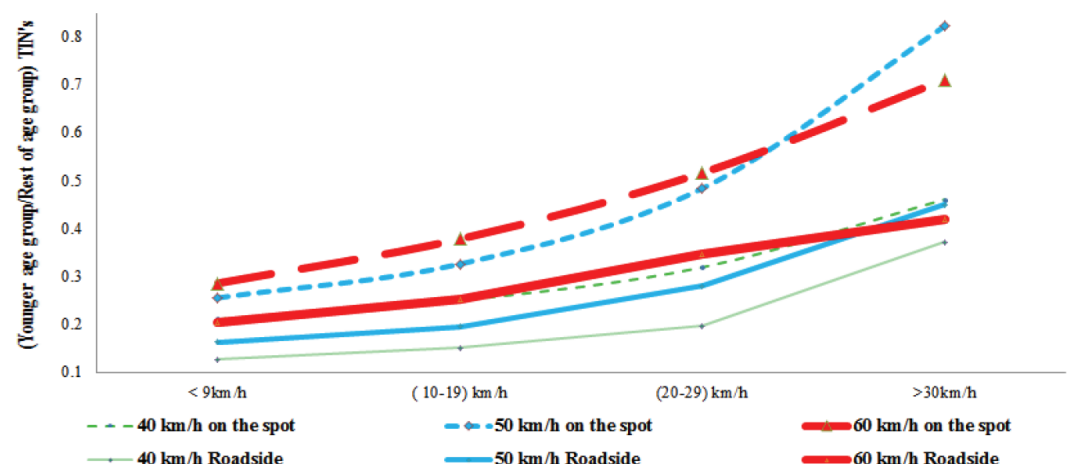

Figure 1: The ratio of younger drivers detected speeding over the rest of all age group at different speeding levels and two types of detections. 
calling for lower speed limits as a preventive measure. The $60 \mathrm{~km} / \mathrm{h}$ is the speed that needs to be strongly monitored particularly as Fig. 1 revealed that it has the highest ratio starting from lower speed and continues to the most extreme speeding level. Although on the $50 \mathrm{~km} / \mathrm{h}$ roads, drivers are taking higher risks.

\subsection{Gender}

A chi-square test for independence was conducted (adopting Pearson values). The study employed 'on the spot' data for three speed limits 40,50 and $60 \mathrm{~km} / \mathrm{h}$. The results of the test have shown that there is significant association between gender and level of speeding $(<9,10-19,20-29,>30 \mathrm{~km} / \mathrm{h})$. For the three speed limits shown in Table 1, the null hypothesis rejected the notion that gender and risk-taking speeding are independent. It means that there is an association between male drivers and risk taking. As male drivers significantly $(p<0.05)$ dominated the risky speeding behaviours compared with female drivers in each of the three speed limits. Hence in each speed limit, male drivers are speeding and taking higher risk than females. A higher $x^{2}$ is observed in the default $50 \mathrm{~km} / \mathrm{h}$ around the local roads. It may also be noted that Cramer's $V$ values have smaller size effect for all the three speed limits.

\subsection{Age groups}

In order to find statistical distances between age group and speeding levels, a correspondence analysis was employed [13-15]. The analysis were performed to the 'on the spot' detection data for the period July 2007-June 2011. The graphs shown in Fig. 2 compare these distances on roads at three different speed limits. They are 40, 50 and $60 \mathrm{~km} / \mathrm{h}$. Younger age group (17-24 years) came with a closer distance to the high risk speeding level (20-29 km/h). Importantly they are also closer to the excessive speed limit ( $>30 \mathrm{~km} / \mathrm{h}$ ).

The same pattern is depicted for the other two higher speed limits. Speeding detected on roads with $40 \mathrm{~km} / \mathrm{h}$ limit, shows old group of drivers are away from the rest of the higher speeding levels. It may seem that old drivers are more cautious in the $40 \mathrm{~km} / \mathrm{h}$ roads. As for the young drivers (25-29 years) they seem to be closer to the high risk speeding level $(20-29 \mathrm{~km} / \mathrm{h})$ in the $40 \mathrm{~km} / \mathrm{h}$ speed limit compared with their position in the other two higher speed limits.

Since the younger age group are dominating in terms of speeding in the $40 \mathrm{~km} / \mathrm{h}$, it is further examined on two different environments namely the school zones (local roads around and outside schools) and non-school zones (roads that belong to shopping strips, Central Business District and work zones). As shown in section 3 below.

Table 1: Chi-square parameters between speeding levels and gender on three speed limits.

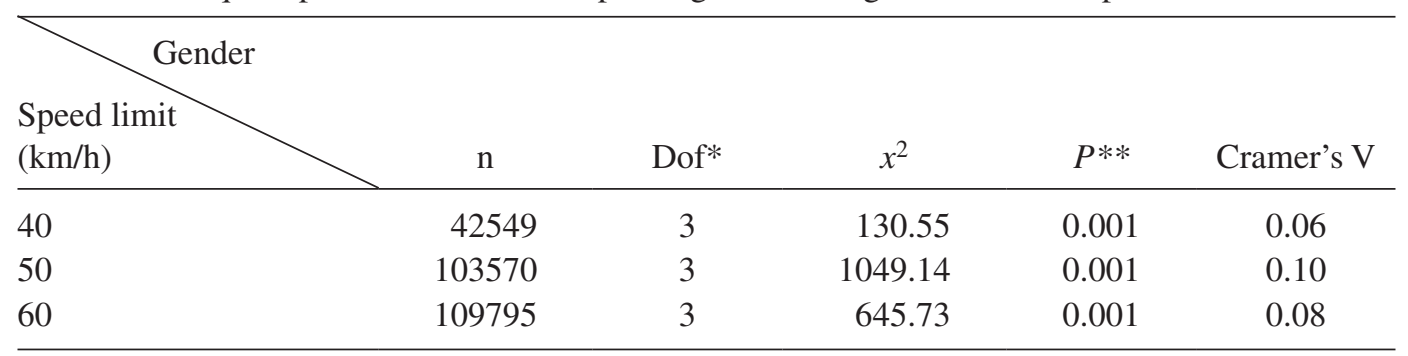

$*$ Degrees of freedom, $* *=<0.05$ confidence level 

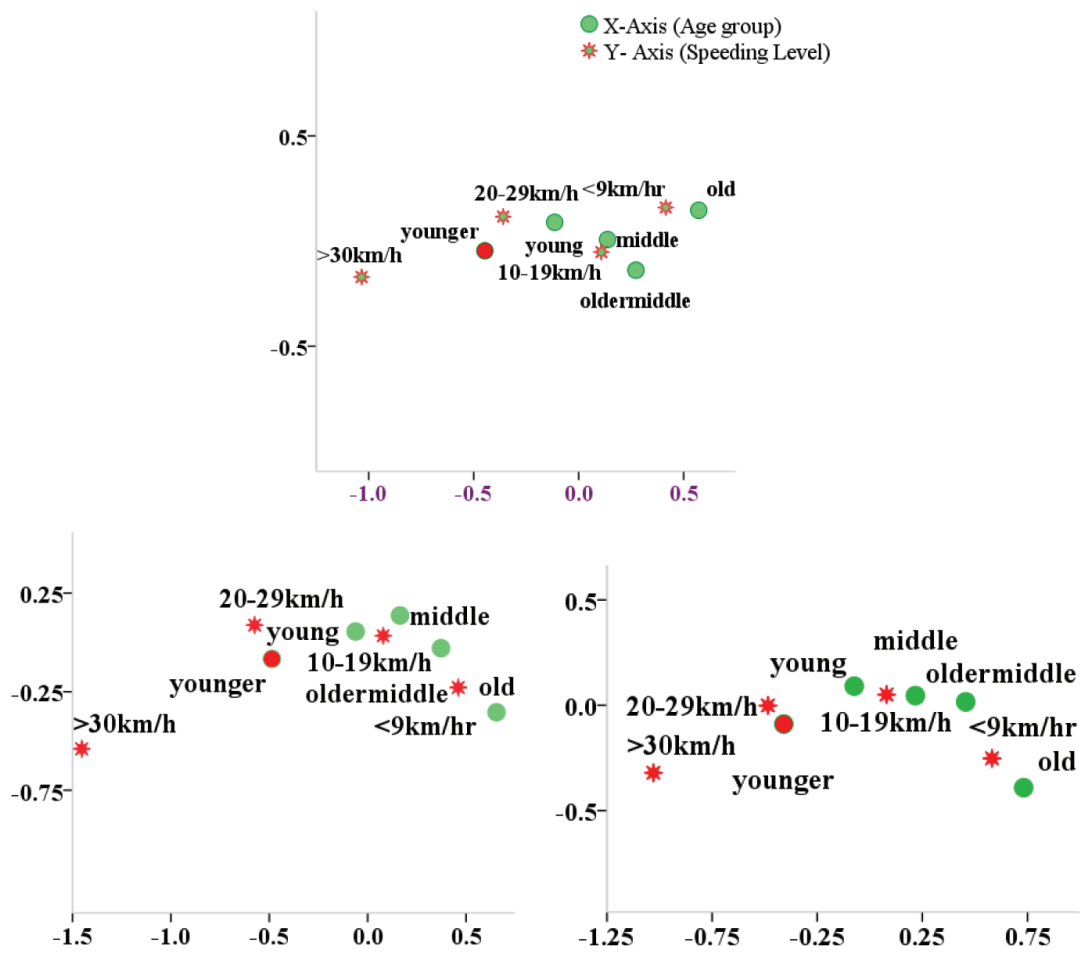

Figure 2: Younger age group compared with other four age groups drivers detected speeding in the $40 \mathrm{~km} / \mathrm{h}$ (above), $50 \mathrm{~km} / \mathrm{h}$ (left) and $60 \mathrm{~km} / \mathrm{h}$ speed limits.

\section{ENFORCEMENT OF $40 \mathrm{KM} / \mathrm{H}$}

This section focuses on the younger drivers in two environments within $40 \mathrm{~km} / \mathrm{h}$ limit, school zone and non-school zone. The school zone data is determined from two sources; the direct school zone source and the other source of data were filtered from the $40 \mathrm{~km} / \mathrm{h}$ speeding data. This latter data were added based on timing of the speeding offence and day of the week (including weekend and public holidays) and distance of each speeding offence from the school zone boundaries. Each case was examined individually and added to the above direct data. A buffer of 10-100 m was used. This is based on the fact that few cases were filtered from the shopping centres strips were school zones existed.

It can be seen from Fig. 3 that the dominance of the 'on the spot' detection, which can lead to target and explore further the speeding risk that younger age group drivers, are taking is the ratio of 'on the spot' over the 'roadside' type are increasing as the speeding level is increasing. Eventually it is vital to expose the tangible importance of the police officers presence on the road and not to rely solely on just cameras spread on the road network [15]. The presence of police officers is a community desire. Therefore on the spot detection should be directed towards non-school zones such as shopping centres and other strips that are busy with both traffic and pedestrian movements.

The paramount importance of knowing how younger driver are contributing to this high risk speeding is considered to be a vital determinant to policy makers in road safety. It was therefore decided to see any close distance between speeding levels and different age groups. Thus, correspondence analysis [16] was employed and it revealed that younger age group is over represented as 
a risk taking group as shown in Fig. 4. It shows that the younger age group of all is fairly close to the highest most extreme speeding level, which is $>30 \mathrm{~km} / \mathrm{h}$, and this over representation is more pronounce on roads that belongs to the non-school zones. It can also be noticed that young age group (25-29 years) were closer to the younger group. The young group are close to the second most dangerous speeding level (20-29 km/h).

Since this younger group is also involved in risky behaviours along school zone, it was decided to unify the age group data (to get rid of the different age range between age groups). As shown in Fig. 5, younger age group remain closer to the extreme speeding level $(>30 \mathrm{~km} / \mathrm{h})$ on both zones, but still closer to the extreme speeding level, on roads belong to the non-school zones.

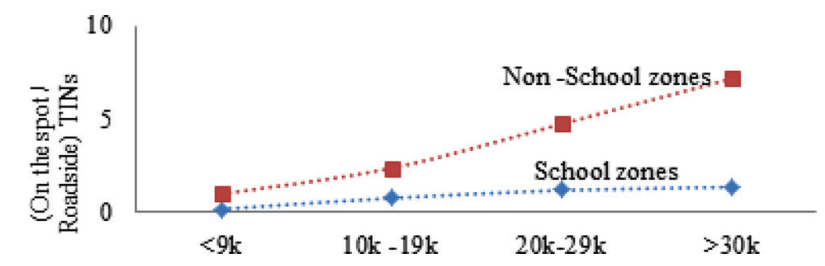

Figure 3: The strength of the on spot detection of offenders with higher speed.

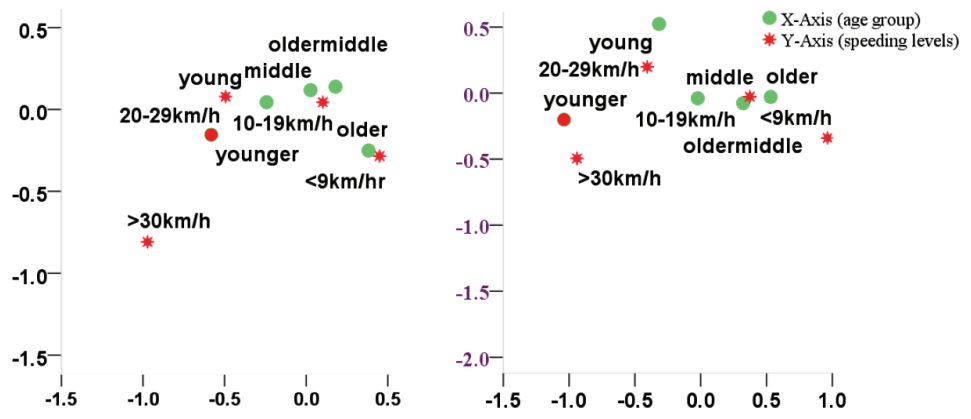

Figure 4: School (left) and non-school 'on the spot' speeding detection: age group vs. risky speeding levels.
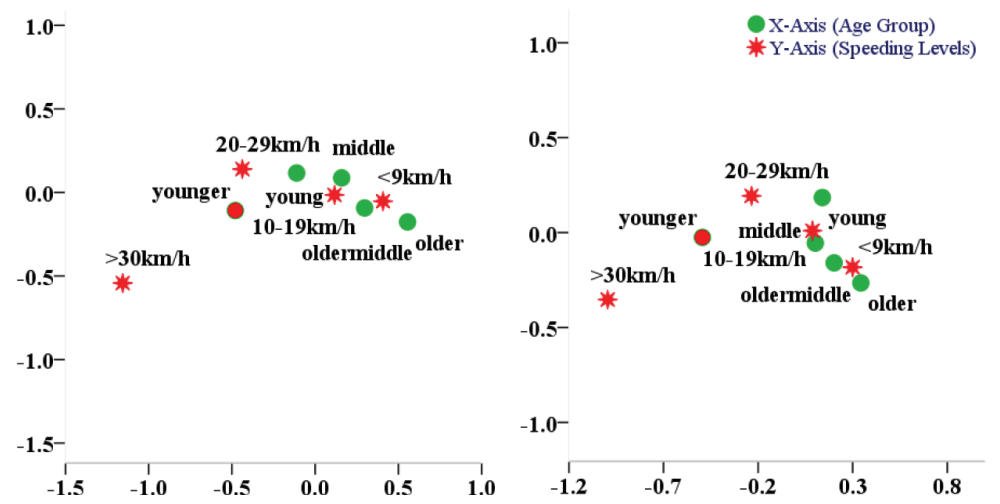

Figure 5: School (left) and non-school (right): Unified frequency age groups vs. speeding levels. 


\section{PEDESTRIAN ROAD CRASHES}

Pedestrian road crashes were found to involve younger age group as offending drivers. Pedestrian road crashes can be a strong indicator into highlighting the risk involvement of different age groups. It can be observed in Fig. 6 that crash data indicated that younger age group (17-24 years), as offending drivers, has a strong representation in terms of risk involvements in hitting pedestrians. All other age groups have shown a lower unit rate, respectively, as age group gets older. The $50 \mathrm{~km} / \mathrm{h}$ speed limit can be sighted as most dangerous, as all groups have recorded highest frequency rate similar to $60 \mathrm{~km} / \mathrm{h}$. Figure 6 depicts that all age groups are contributing to hitting pedestrians in 50 and $60 \mathrm{~km} / \mathrm{h}$ at different frequency rates. As younger age group remains the highest contributor to risk.

Main roads crash data of Perth metropolitan in WA were analysed to produce severity percentages of pedestrian victims involved in crashes 2006-2011. Percentages of pedestrian crash severity were higher on roads with higher speed road such as the $60 \mathrm{~km} / \mathrm{h}$ limit (see Table 2). In terms of the low speed limit roads such as the $40 \mathrm{~km} / \mathrm{h}$, it was found that non-school zones roads had higher severity percentages of pedestrian crashes than those that have occurred around school zones. This is more pronounced in terms of the Killed and Seriously Injured (KSI) pedestrians. Table 2 reveals that the higher the speed limit, the higher the harm in terms of pedestrian crashes.

\section{DISCUSSIONS}

Enforcement is one crucial dimension in the triangle of road safety that compliments and sustains engineering and education. Despite $60 \mathrm{~km} / \mathrm{h}$ being a higher speed of the three limits, it was found that younger drivers were speeding more than any other age groups in the three speed limits

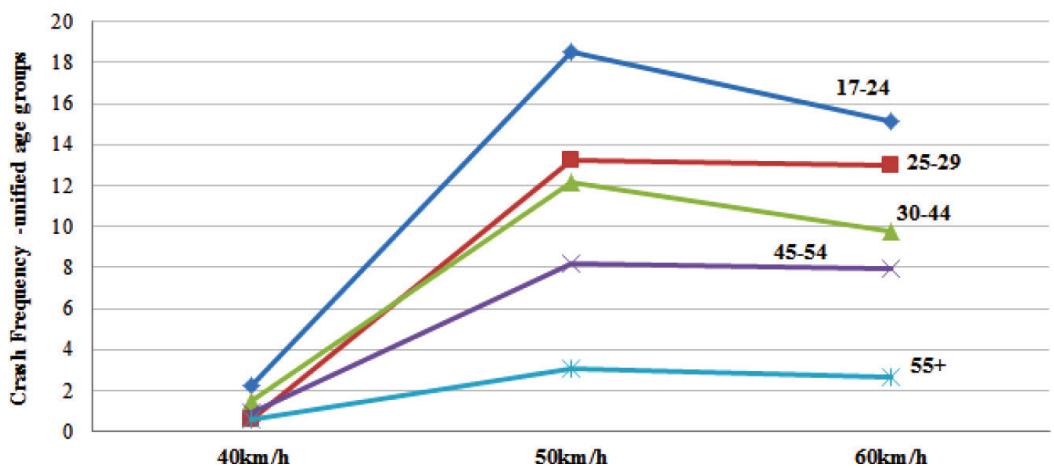

Figure 6: Driver's age groups that have hit pedestrians on three speed limits frequency with yearly based unified rate, using, 2006-2011 crash data.

Table 2: Percentages of Pedestrian crash severity.

\begin{tabular}{lcccc}
\hline Crashes & $\begin{array}{c}40 \mathrm{~km} / \mathrm{h} \\
\text { School }\end{array}$ & $\begin{array}{c}40 \mathrm{~km} / \mathrm{h} \\
\text { Non-school }\end{array}$ & $50 \mathrm{~km} / \mathrm{h}^{* *}$ & $60 \mathrm{~km} / \mathrm{h} * *$ \\
\hline KSI/Total & 13 & 25 & 32 & 42 \\
All injuries/total* & 47 & 55 & 65 & 72 \\
\hline$*$ = total includes property damages, **= all roads in suburbs under study except $40 \mathrm{~km} / \mathrm{h}$.
\end{tabular}


40,50 and $60 \mathrm{~km} / \mathrm{h}$. The $50 \mathrm{~km} / \mathrm{h}$ may need to be targeted for audit, as results of this paper explained how drivers of all ages are contributing to cause pedestrian crashes in the $50 \mathrm{~km} / \mathrm{h}$ similar to that of $60 \mathrm{~km} / \mathrm{h}$. It may be that roads of these two speed limits are high in number and in lengths, but this should not be a reason not to audit such road and to make them safe for road users. In fact research in Australia has found that a pedestrian would hardly survive if hit with $60 \mathrm{hm} / \mathrm{h}$ compared with $40 \mathrm{~km} / \mathrm{h}$ where a chance of being killed is $25 \%$ only [17]. Due to the recent rise of pedestrian fatalities in roads with $60 \mathrm{~km} / \mathrm{h}$ limits, the Curtin-Monash Accident Research Centre is calling to lower such limit speed limit near shopping centres and hospitals [18]. This dangerous and sometime excessive speeding came mainly from the younger group drivers between the ages of 17 and 24 years. This study found that male drivers in particular are speeding more than female drivers. Pedestrian crash data also supported this evidence in finding that most drivers who hit pedestrians belong to this younger age group. The study also found younger age group to be at the centre of concern around school zones and particularly around $40 \mathrm{~km} / \mathrm{h}$ roads away from schools such nonschool zones.

Experience outside Australia showed similar concern for young drivers, for instance according to the Dutch Institute for Road Safety Research SWOV, the difference in crash rates between young (18-24 years) and older drivers (30-59 years) is increasing. It found that 20 years ago, the fatal crash involvement rate of young motorists was three times higher than that of older motorists; today it is six times higher. It is recommended that roads with possible conflicts between cars and unprotected road users may need to adopt $40 \mathrm{~km} / \mathrm{h}$ speed limit or even lower [19]. A latest proposal is been discussed in Britain could see younger drivers be banned from carrying non-family passengers. A proposal by the UK government as younger drivers under the age of 25 represent only one in eight, but they account for one-third of the number of people who die on UK roads [20]. Recently in Melbourne, the idea of night curfew for younger driver stood little chance as 16,000 road users survey showed only $28 \%$ accepted the idea for a night curfew between $10 \mathrm{pm}$ and 7 am [21]. In a similar fashion in the UK, only $34 \%$ of road users agreed about young driver's night curfew between $11 \mathrm{pm}$ and 4 am [22]. Both survey results suggest that more education and training are needed.

Overall, there is a need for sustainability of enforcing a change in young driver's risky behaviour towards safer speed. It is recommending that two levels need to be targeted in parallel along with enforcement. First a municipal programme may need to be targeting $60 \mathrm{~km} / \mathrm{h}$ roads along with $50 \mathrm{~km} / \mathrm{h}$ roads and accordingly prepare 'an audit plan' to lower speed limit on these roads based on harm scaling such as accident history or speeding history and other engineering measures. Second authorities may need to focus on younger drivers' licence regulations in terms of speeding violations and accidents history and more real life scenarios training. Authorities may need to be even more stringent with existing regulations when required with more local young driver scenarios to be highlighted. With such policy direction, a high returns on road safety may be achieved that can assist in producing sustainable safer roads.

Overall, there needs to be sustainability in terms of mobility such as the one discussed by Schoon [23] on the implicit involvement of road safety in sustainable mobility, where traffic management and mobility management are the core of such involvement in addition to vital vehicle management. The report added that detailed data is required for the purpose of quantification, particularly data that involve changes in mobility and behaviour as a result of the sustainability mobility measures. Such direction may contribute to reduce fatalities especially those that involve young drivers in Perth.

\section{ACKNOWLEDGEMENT}

The authors would like to thank Chris Canny, the Assistant Director of the Academic Development of the WA Police, for her valuable support and acknowledgement of this paper. Thanks to the 
Academic Research Administration Unit of the WA police for supplying the data and clarifying labelling and other data inquiries. The authors also thank Thandar Lim of Main Roads WA for providing and discussing the Perth urban road crashes.

\section{REFERENCES}

[1] Smart, D., Vassallo, S., Sanson, A., Cockfield, S., Harris, A., Harrison. W. \& McIntyre, A. In the Driver's Seat Understanding Young Adults Driving Behaviour, Australian Institute of Family Studies: Melbourne, 2005.

[2] Ramsey, M., WA Speed Cameras 'not Cutting Toll', Australian Associated Press, August 02, 2012.

[3] Ramsey, M., Worry Over WA's Soaring Road Toll After String of Fatal Accidents, Australian Associated Press, July 02, 2012.

[4] Cavallo, A. \& Triggs, T.J., Directions for Improving Young Driver Safety within Victoria: A Discussion Paper, Monash University Accident Research Centre: Melbourne, Victoria, 1996.

[5] World Health Organisation (WHO), Speed management: a road safety manual for decision makers and practitioners, Geneva, Global Road Safety Partnership, 2008.

[6] Austroads, Balance between harm reduction and mobility in setting speed limits: a feasibility study, Report 272/05, 2005.

[7] Elvik, R., The Power Model of the relationship between speed and road safety, Institute of Transport Economics. Oslo, Report no. 1034, 2009.

[8] ETSC - European Transport Safety Council, Managing Speed towards Safe and Sustainable Road Transport, pp. 1-34, 2008.

[9] Elvik, R., Cost-benefit analysis of police enforcement: implications of choice of framework for cost-benefit analysis of police enforcement, pp. 1-75, 2001. doi: http://dx.doi.org/10.1037/ e313122004-003

[10] Palamara, P.G. \& Stevenson, M.R., A Longitudinal Investigation of Psychosocial Risk Factors for Speeding Offences among Young Motor Car Drivers, Department of Public Health, Injury Research Centre. The University of Western Australia, RR128, 2003. doi: http://dx.doi. org/10.1037/e620762012-001

[11] Paddenburg, T., Half young WA drivers text while at the wheel, The Sunday Times, July 24, 2010.

[12] Paddenburg, T. Warning to young drivers, The Sunday Times, May 18, 2013.

[13] Clausen, S.E., Applied Correspondence Analysis. Sage publication: London, 1998.

[14] Greenacre, M.J., Multiple Correspondence Analyses, 2nd ed., Chapman \& Hall/CRC: Boca Raton, 2007.

[15] Ebrahim, Z. \& Nikraz, H., Harm minimisation in a school zone: a strategy for sustaining pedestrian safety. Wit Transactions on the Built Environment, Vol. 128, () 2012. WIT Press. doi: 10.2495/UT120151. 2012. doi: http://dx.doi.org/10.2495/ut120151

[16] Le Roux, B. \& Rouanet, H., Multiple Correspondence Analyses. Sage publication: London, 2010. doi: http://dx.doi.org/10.4135/9781412993906

[17] Corben, B., Senserrick, T. Cameron, M. \& Richnitzer, G., Development of the visionary research model: application to the car/pedestrian conflict. Monash University Accident Research Centre, Report 229. 2004

[18] O'Connell, R., Road safety expert calls for 30km/h limit trials. The West Australian, 7 February, 2012. 
[19] SWOV, National Road Safety Exploration for 2005 - 2020, advancing sustainable safety in brief, 2006.

[20] Millward, D. \& Hall, J., Young drivers could be banned from carrying non-family passengers, The Telegraph. 16 Nov, 2012.

[21] Moor, K., Call to reduce drink-driving limit to .05 has been blown away, Herald Sun October 23, 2012.

[22] The Guardian, Should there be a curfew for young, October 4, 2012.

[23] Schoon, Ing, C.C., Duurzame Mobiliteit: ook verkeersveiligheidseffecten in beeld brengen (In Dutch, Summary in English), SWOV, R-23, 2011. 